\title{
Conservation of Latin America freshwater biodiversity: beyond political borders
}

\author{
Mathias Kuemmerlen ${ }^{1}$ (D) - Angélica María Batista-Morales ${ }^{2} \cdot$ Andreas Bruder $^{3}$. \\ Eren Turak $^{4}$ - Fabio de Oliveira Roque ${ }^{5,6}$
}

Received: 17 June 2021 / Revised: 20 January 2022 / Accepted: 25 January 2022 / Published online: 5 March 2022 (c) The Author(s) 2022

\begin{abstract}
Latin America's tremendous socio-cultural and biological diversity has evolved along tightly intertwined, far-reaching river networks. Decisions taken by any one country, may have strong impacts on the regional and even global biodiversity conservation agenda, such as the Convention on Biological Diversity. Here we comment on four perspectives complementing actions suggested by Azevedo-Santos et al. (2021) in their Commentary "Conservation of Brazilian freshwater biodiversity: Thinking about the next 10 years and beyond". This contribution aims at attaining an effective conservation of freshwater biodiversity in Latin America, particularly in the context of the ongoing negotiations on the Global Biodiversity Framework. Our suggestions put forward cross-border perspectives, urging governments to engage in actions that consider the reality of and threats to transnational ecosystems such as many river basins of Latin America and elsewhere.
\end{abstract}

Keywords Transnational basins - Freshwater biodiversity - Convention on Biological Diversity $\cdot$ Monitoring $\cdot$ Ecological connectivity

Communicated by James Tony Lee.

Mathias Kuemmerlen

m.kuemmerlen@tcd.ie

1 Department of Zoology, School of Natural Sciences, Trinity Centre for the Environment, Trinity College Dublin, The University of Dublin, College Green, Dublin, Ireland

2 Instituto de Investigación de Recursos Biológicos Alexander von Humboldt, Bogotá, Colombia

3 Institute of Microbiology, University of Applied Sciences and Arts of Southern Switzerland, Mendrisio, Switzerland

4 Department of Planning, Industry and Environment, Parramatta, NSW, Australia

5 Instituto de Biociências, Universidade Federal de Mato Grosso do Sul, Campo Grande, Mato Grosso do Sul, Brazil

6 Centre for Tropical Environmental and Sustainability Science (TESS) and College of Science and Engineering, James Cook University, Cairns, Qld, Australia 


\section{Introduction}

The rich freshwater biodiversity of Brazil is addressed by Azevedo-Santos et al. (2021), along with examples of needed actions to conserve it. Five actions are described: (1) a national plan to reduce threats, (2) restoration of freshwater ecosystems, (3) implementing protected areas efficient in protecting freshwater environments, (4) more investment in research and (5) promoting science communication and outreach. The authors argue that these actions should guide the parties of the Convention on Biological Diversity (CBD) when engaging in discussions with Brazil on developing an improved agenda to conserve biodiversity for the post-2020 Global Biodiversity Framework (GBF).

The actions raised by Azevedo-Santos et al. (2021) are highly relevant, but not unique to Brazil as they apply to most other countries in Latin America. We acknowledge that national circumstances relative to political cycles and specific national legislations differing in regulations and compliance rigor, may constrain particular challenges to national territories (Torremorell et al., 2021). However, attempts to successfully counteract threats to freshwater biodiversity, intensify their research and promote their restoration, must move beyond national boundaries and be tackled at the catchment scale. A regional roadmap guiding such attempts should: (a) seek inspiration from success stories in Latin America and elsewhere, (b) exploit synergies with existing networks and organizations, (c) be scalable across regions and (d) be widely communicated.

We propose and illustrate four perspectives complementing the above actions to effectively protect the remarkable freshwater biodiversity of Latin America (Reis et al. 2016). Our contributions represent a global south perspective echoing recent pledges to better inform and further enhance the ability of global (GBF) and continental (e.g. Biodiversity Strategy of the European Union [EU]) initiatives to halt and reverse the rapid global decline of freshwater biodiversity (van Rees et al., 2021). We share insights based on numerous discussions led while establishing the Freshwater Biodiversity Observation Network in Latin America (FWBON, https://geobon.org/bons/thematic-bon/freshwater-bon/) to support the dialogue leading to the 2050 Vision for Biodiversity of the CBD, currently under discussion in the context of the GBF.

Develop and support transnational initiatives National, regional or global freshwater biodiversity conservation goals cannot be achieved without coordinating actions across large river basins, which are linked through long and dense river networks. Many river basins in Latin America, including some of the largest worldwide, cross national borders (e.g. Amazonas, Orinoco, La Plata, Bravo del Norte, Lempa) making up more than 37\% of Central and almost $60 \%$ of South America (UNEP 2008; GWP 2011). Nations thus need to establish policies and actions for transnational basin management (Azevedo-Santos et al. 2019), while GBF management elements and indicators have to be effective at this scale. The citizen science project Ictio (www.ictio.org), collecting observations on fish across the Amazon to understand their migration behaviour (Johnson et al., 2021), is a good example. The associated smart-phone application is accessible to many stakeholders because it was launched in two languages (Portuguese and Spanish). Such transnational research networks can streamline collaboration and initiatives, provided they have financial support. For instance, the ZICOSUR Programme "Conservation, sustainable use and good governance of biodiversity in four vulnerable biomes in the center of South America" launched within the 
EU framework "Biodiversity for life" strategy (B4Life), promotes the conservation of the Rio Paraguay catchment and four crucial ecosystems therein: Pantanal, Bosque Chiquitano, Cerrado and Gran Chaco (United Nations Convention to Combat Desertification, 2019).

Further, freshwater biodiversity could benefit from existing structures regulating interactions between countries when managing water in transnational basins. International River Basin Organizations (IRBOs; Milman and Gerlak 2020) for example, engage in hydrodiplomacy and foster scientific collaboration across borders to support decision-making processes. Latin American countries have experience managing catchments based on scientific evidence and citizen participation, usually coordinated by regional or local management committees. However, programme implementation and continuity differ, partially because of the existence of a vast informal sector which neither complies with legal norms, nor responds to economic and monitoring instruments (Dourojeanni, 2001). Although structures in Latin America lack the reach and the commitment of those in the EU (e.g. Water Framework Directive; European Union, 2000), we envision organizations similar to IRBOs engaging in freshwater-biodiversity-diplomacy next to the necessary hydro-diplomacy. These would build upon existing international alliances such as the Amazon Cooperation Treaty Organization (ACTO), which promotes the sustainable development of the Amazon Basin or the Central American Integration System (SICA) which pursues regional integration, including nature conservation. Failure to manage transboundary basins and their ecosystems collectively, can result in conflicts among nations (e.g. Rios-Touma et al., 2020).

Develop and harmonize transnational data collection and monitoring Freshwater biodiversity monitoring in Latin America is infrequently grounded in laws or formal regulations, often leading to spatially isolated and non-standardized data collection (Feio et al. 2021). Thus, there is a need for regionally harmonized freshwater monitoring and bioindicators that provide critical information on the status and trends of biodiversity, which are universally accessible and interpretable by different stakeholders. This entails data acquisition and handling using compatible methods at multiple scales to enable a comprehensive evaluation of the impacts and take appropriate actions against anthropogenic impairments and climate change (Barthem et al. 2004; Heino et al. 2020).

Building on harmonized data, key variables and indices can be computed at the required scale (e.g. cross-border catchment), yielding information for environmental management, conservation and policy-making. The concept of essential biodiversity variables (EBVs; Pereira et al. 2013) is a prominent example, directly linked to meaningful conservation indicators (e.g. Living Planet Index) and to the Aichi Biodiversity Targets (Proença et al. 2017), including the strategic goals B and C (Targets 5-13; Schmeller et al., 2018). BON in a Box (https://boninabox.geobon.org) assembles suitable tools for standardized collection and management of data, assessing measure effectiveness and monitoring biodiversity trends based on EBVs. A global approach for applying EBVs to freshwater biodiversity was advanced by GEOBON's Freshwater Working Group including specific priorities for the 2020 Aichi targets and the 2030 SDG Goals (Turak et al. 2017), of which globally harmonized freshwater macroinvertebrate sampling protocols are being progressed (IUCN SSC TF: https://www.iucn.org/commissions/ssc-groups/cross-cutting/ global-freshwater-macroinvertebrate-sampling-protocols-task-force). 
Increase engagement in a pluricultural region and enable participatory monitoring Analogous to its biodiversity, Latin America has a tremendous socio-cultural diversity, with the Amazon basin alone being home to more than 300 indigenous groups (Hoorn, et al. 2010). Embracing this diversity and integrating different indigenous and traditional cultures, and their perspectives in biodiversity conservation is essential (Frainer et al. 2020). For example, having lived in the Amazon rainforest for millennia, indigenous peoples (Barlow, et al. 2012) monitor key food resources, including turtles and fish, using self-developed systems that are formally incorporated into national biodiversity monitoring in Brazil (Roque, et al., 2018). In the department of Amazonas in Colombia, indigenous communities have an impact on decision-making of territorial planning schemes and regulations of the Ministry of the Environment through their involvement in monitoring schemes of fishery resources, riparian vegetation and river dolphins (Trujillo \& Duque, 2014). A widespread integration of local indigenous and traditional ecological knowledge into freshwater biodiversity monitoring should promote inclusive decision-making processes in catchment-wide management (Heino et al., 2020; Thompson et al., 2020).

A fair representation of all stakeholders in freshwater biodiversity conservation is both an opportunity and a great challenge in Latin America. Governments comprise a multitude of institutions with different priorities and modes of operation across the region and even within national borders (e.g. federal states in Brazil and México; Feio et al. 2021). Effective conservation strategies are, therefore, challenging, regardless of their spatial scale. Furthermore, widespread social inequalities are considered as implementation barriers of large-scale conservation initiatives. Despite these challenges, traditional and indigenous groups from different countries have created collaboration spaces opening novel avenues for transnational participatory initiatives. The programs "Territories and areas conserved by indigenous peoples and local communities” (ICCA Consortium; https://www.iccaconsortium.org/index.php/es/latin-america-es) is just one example.

Scalable biodiversity monitoring initiatives led and managed by local stakeholders (i.e. indigenous and traditional cultures; farmers cooperatives) at diverse levels of organization, can be aggregated to match the spatial scale of specific conservation objectives (Roque et al. 2018). Here, the potential of participatory programs promoting sustainable practices at the community level, such as the Programa Bandera Azul Ecológica of Costa Rica (MoraAlvarado and Chávez-Aguilar, 2009) could be harnessed. Such an approach enables sufficient monitoring capacities, effectively implements conservation strategies and increases the acceptance of environmental management measures. Moreover, conservation and restoration initiatives involving freshwater biodiversity could promote economic opportunities for local communities, such as successful market initiatives in Latin America on carbon and catchment protection (Grieg-Gran et al., 2005). Finally, transdisciplinary research on the relationship between freshwater biodiversity and human well-being can trigger much needed dialogues within society. The recently published report "Water: biodiversity, ecosystem services and human well-being in Brazil" by the Brazilian Platform on Biodiversity and Ecosystem Services (https://www.bpbes.net.br/produto/agua/) is a valuable illustration.

Link freshwater conservation in Latin America with global economies The links between local economies and global trade are a critical aspect of freshwater biodiversity conservation in Latin America. Most economies rely heavily on agricultural commodities (e.g. 
beef, soy, maize, sugarcane, coffee) and raw materials (e.g. gold, copper, lithium, oil) which severely impact the environment and freshwater ecosystems in particular (Castello et al. 2013). To reduce this threat, it is fundamental to empower governmental environmental protection agencies (Torremorel et al. 2021) to enforce traceability and transparency in the supply chain through the declaration of environmental impact in product information, including impacts on freshwater ecosystems and biodiversity. This would allow informed choices for consumers and force producers to align with climatic, biodiversity and social justice. Fairly traded and organically produced commodities are positive first steps, but full traceability and transparency will fundamentally change international trade, reducing pressure on freshwater ecosystems and biodiversity. The Transparency for Sustainable Economies (www.trase.earth) initiative, for instance, monitoring deforestation caused by soy and cattle production in Latin America (e.g. zu Ermgassen et al., 2020), has opened new perspectives to commodity chains and may represent a new opportunity to link the status of freshwater biodiversity to economic development (i.e. Mercosur-EU trade agreement).

\section{Conclusions}

The ongoing GBF development recognizes that urgent policy action is required at all scales to protect and restore ecosystems and biodiversity. However, the proposed GBF version aims at developing global strategies and implementing policy actions with a strong emphasis on the national scale. Thus, the decisions of one country can have significant effects on others in a transnational basin. The conflict potential becomes tangible when considering aquatic biodiversity in a shared river network. Explicitly recognizing this will certainly guide governments in devising actions, objectives, monitoring elements and indicators that consider the reality of and threats to transnational ecosystems such as the large river basins of Latin America. As most major international challenges will only be solved collectively, strengthening regional ties is of utmost priority.

The prospects for such a collaboration in Latin America are strengthened by the absence of major historical conflicts related to hydrological issues. Moreover, the deep admiration shown by the nations and peoples for the natural capital that has been bestowed upon them, has resulted in several basin-wide initiatives discussed here and provide a robust foundation for mutual confidence and political trust to advance international transdisciplinary cooperation (Biswas, 2011). The GBF is an opportunity for exemplary, cross-border agreements committed to protecting and improving freshwater biodiversity and ecosystems. This promise for positive change in Latin America is immensely significant given that the Neotropics are home to a third of the world's freshwater vertebrate species (Balian et al. 2007) and that these are facing formidable threats to its persistence.

Funding Not applicable.

Open Access funding provided by the IReL Consortium

Availability of data and material Not applicable.

Code Availability Not applicable. 


\section{Declarations}

Conflicts of interest/competing interests Not applicable.

Open Access This article is licensed under a Creative Commons Attribution 4.0 International License, which permits use, sharing, adaptation, distribution and reproduction in any medium or format, as long as you give appropriate credit to the original author(s) and the source, provide a link to the Creative Commons licence, and indicate if changes were made. The images or other third party material in this article are included in the article's Creative Commons licence, unless indicated otherwise in a credit line to the material. If material is not included in the article's Creative Commons licence and your intended use is not permitted by statutory regulation or exceeds the permitted use, you will need to obtain permission directly from the copyright holder. To view a copy of this licence, visit http://creativecommons.org/licenses/by/4.0/.

\section{References}

Azevedo-Santos VM, Frederico RG, Fagundes CK et al (2019) Protected areas: A focus on Brazilian freshwater biodiversity. Divers Distrib 25:442-448. https://doi.org/10.1111/ddi.12871

Azevedo-Santos VM, Rodrigues-Filho JL, Fearnside PM et al (2021) Conservation of Brazilian freshwater biodiversity: Thinking about the next 10 years and beyond. Biodivers Conserv 30:235-241. https://oi. org/10.1007/s10531-020-02076-5

Balian EV, Segers H, Martens K, Lévéque C (2007) The freshwater animal diversity assessment: an overview of the results. FADA $627-637$

Barlow J, Gardner TA, Lees AC, Parry L, Peres CA (2012) How pristine are tropical forests? An ecological perspective on the pre-Columbian human footprint in Amazonia and implications for contemporary conservation. Biol Conserv 151:45-49. https://doi.org/10.1016/j.biocon.2011.10.013

Barthem R, Charvet-Almeida P, Montag L, Lanna A (2004) Global International waters assessment Amazon basin, GIWA regional assessment 40 b. GIWA Regional assessment reports 76

Biswas AK (2011) Transboundary Water Management in Latin America: Personal Reflections. Water Resour Dev 27:423-429

Castello L, McGrath DG, Hess LL et al (2013) The vulnerability of Amazon freshwater ecosystems. Conserv Lett 6:217-229. https://doi.org/10.1111/conl.12008

CBD-WG2020 (2020) Update of the zero draft of the post-2020 global biodiversity framework. CBD/ POST2020/PREP/2/1. Preparations For The Post-2020 Biodiversity Framework. Convention on Biological Diversity, UN Enviroment Program. 9p. https:/www.cbd.int/doc/c/3064/749a/0f65ac7f9def867 07f4eaefa/post2020-prep-02-01-en.pdf

Dourojeanni R, Axel (2001) Water management at the river basin level: challenges in Latin America. Recursos Naturales E Infraestructura 29. CEPAL/ECLAC, Natural Resources and Infrastructure Division, Santiago

zu Ermgassen EKHJ, Ayre B, Godar J et al (2020) Using supply chain data to monitor zero deforestation commitments: an assessment of progress in the Brazilian soy sector. Environ Res Lett 15:035003. https://doi.org/10.1088/1748-9326/ab6497

European Union (2000) Directive 2000/60/EC of the European Parliament of the Council of 23 October 2000 establishing a framework for Community action in the field of water policy. OJEC L327:1-72

Feio MJ, Hughes RM, Callisto M et al (2021) The Biological Assessment and Rehabilitation of the World's Rivers: An Overview. Water 13:371. https://doi.org/10.3390/w13030371

Frainer A, Mustonen T, Hugu S et al (2020) Opinion: Cultural and linguistic diversities are underappreciated pillars of biodiversity. PNAS 117:26539-26543. https://doi.org/10.1073/pnas.2019469117

Grieg-Gran M, Porras I, Wunder S (2005) How can market mechanisms for forest environmental services help the poor? Preliminary lessons from Latin America. World Dev 33:1511-1527

GWP (2011) Situación de los recursos hídricos en Centroamérica: hacia una gestión integrada. Programa de Desarrollo de Zonas Fronterizas en América Central (ZONAF), de la Unión Europea (UE) y el Banco Centroamericano de Integración Económica (BCIE)

Heino J, Culp JM, Erkinaro J et al (2020) Abruptly and irreversibly changing Arctic freshwaters urgently require standardized monitoring. J Appl Ecol 57:1192-1198. https://doi.org/10.1111/1365-2664.13645

Hoorn C, Wesselingh FP, Steege H, ter et al (2010) Amazonia Through Time: Andean Uplift, Climate Change, Landscape Evolution, and Biodiversity. Science 330:927-931. https://doi.org/10.1126/science.1194585 
Johnson N, Druckenmiller ML, Danielsen F, Pulsifer PL (2021) The Use of Digital Platforms for Community-Based Monitoring. Bioscience 71:452-466. https://doi.org/10.1093/biosci/biaa162

Milman A, Gerlak AK (2020) International river basin organizations, science, and hydrodiplomacy. Environ Sci Policy 107:137-149. https://doi.org/10.1016/j.envsci.2020.02.023

Mora-Alvarado DA, Chavez-Aguilar A (2009) Aporte del Programa Bandera Azul Ecológica en la lucha contra el cambio climático en Costa Rica. Revista Tecnología en Marcha 32:158-168. https://doi. org/10.18845/tm.v32i10.4889

Pereira HM, Ferrier S, Walters M et al (2013) Essential biodiversity variables. Science 339:277-278

Proença V, Martin LJ, Pereira HM et al (2017) Global biodiversity monitoring: From data sources to Essential Biodiversity Variables. Biol Conserv 213:256-263. https://doi.org/10.1016/j.biocon.2016.07.014

van Rees CB, Waylen KA, Schmidt-Kloiber A et al (2021) Safeguarding freshwater life beyond 2020: Recommendations for the new global biodiversity framework from the European experience. Conserv Lett 14:e12771. https://doi.org/10.1111/conl.12771

Reis RE, Albert JS, Di Dario F et al (2016) Fish biodiversity and conservation in South America. J Fish Biol 89:12-47. https://doi.org/10.1111/jfb.13016

Rios-Touma B, Kondolf GM, Walls S (2020) Impacts of sediment derived from erosion of partially-constructed road on aquatic organisms in a tropical river: The Río San Juan, Nicaragua and Costa Rica. PLoS ONE 15:e242356. https://doi.org/10.1371/journal.pone.0242356

Roque F, de O, Uehara-Prado M, Valente-Neto F et al (2018) A network of monitoring networks for evaluating biodiversity conservation effectiveness in Brazilian protected areas. PECON 16:177-185. https:// doi.org/10.1016/j.pecon.2018.10.003

Schmeller DS, Weatherdon LV, Loyau A et al (2018) A suite of essential biodiversity variables for detecting critical biodiversity change. Biol Rev 93:55-71. https://doi.org/10.1111/brv.12332

Thompson K-L, Lantz T, Ban N (2020) A review of Indigenous knowledge and participation in environmental monitoring. Ecol Soc 25. https://doi.org/10.5751/ES-11503-250210

Torremorell A, Hegoburu C, Brandimarte AL et al (2021) Current and future threats for ecological quality management of South American freshwater ecosystems. Inland Waters 0:1-16. https://doi.org/10.1080 /20442041.2019.1608115

Trujillo F, Duque SR (eds) (2014) Los humedales de Tarapoto: aportes al conocimiento sobre su biodiversidad y uso. Serie humedales de la Amazonia y Orinoquia. Fundación Omacha, Corpoamazonia, Universidad Nacional Sede Leticia. $400 \mathrm{p}$

Turak E, Harrison I, Dudgeon D et al (2017) Essential Biodiversity Variables for measuring change in global freshwater biodiversity. Biol Conserv 213:272-279. https://doi.org/10.1016/j.biocon.2016.09.005

United Nations Convention to Combat Desertification (2019) The Global Land Outlook, Latin America and the Caribbean Thematic Report, Bonn, Germany

UNEP (2008) Hydropolitical vulnerability and resilience along international waters: Latin America and the Caribbean. United Nations Environmental Programme

Publisher's note Springer Nature remains neutral with regard to jurisdictional claims in published maps and institutional affiliations. 